\title{
The effect of positive end-expiratory pressure on cardiac output and oxygen delivery during cardiopulmonary resuscitation
}

Yosef Levenbrown ${ }^{1,2^{*}}$ D, Md Jobayer Hossain ${ }^{3,4}$, James P. Keith ${ }^{5}$, Katlyn Burr ${ }^{5}$, Anne Hesek ${ }^{3}$ and Thomas Shaffer $r^{6,7}$

\section{* Correspondence:}

yoseflevenbrown@gmail.com

Work completed at Nemours

Biomedical Research, Wilmington,

DE.

${ }^{1}$ Division of Pediatric Critical Care, Nemours/Alfred I. duPont Hospital for Children, 1600 Rockland Road, Wilmington, DE 19803, USA

${ }^{2}$ Department of Pediatrics, Sidney Kimmel Medical School, Thomas Jefferson University, Philadelphia, PA, USA

Full list of author information is available at the end of the article

\begin{abstract}
Background: Positive end-expiratory pressure (PEEP) is used to optimize oxygenation by preventing alveolar collapse. However, PEEP can potentially decrease cardiac output through cardiopulmonary interactions. The effect of PEEP on cardiac output during cardiopulmonary resuscitation (CPR) is not known.
\end{abstract}

Methods: This was a preclinical randomized, controlled, animal study conducted in an animal research facility on 25 Landrace-Yorkshire pigs. After inducing cardiac arrest, CPR was performed with LUCAS 3. During CPR, pigs were ventilated at a PEEP of $0,5,10,15,20 \mathrm{cmH}_{2} \mathrm{O}$ (randomly determined via lottery) for 9 min. Cardiac output, obtained via ultrasound dilution, and $\mathrm{PaO}_{2}$ were measured, and oxygen delivery calculated for each PEEP.

Results: A mixed-effects repeated-measures analysis of variance was used to compare the baseline value adjusted mean cardiac output, $\mathrm{PaO}_{2}$, and oxygen delivery between PEEP groups. Least significant difference test was used to conduct pairwise comparisons between PEEP groups. To determine optimum PEEP, Gaussian mixture model was applied to the adjusted means of cardiac output and oxygen delivery. Increasing PEEP to 10 and higher resulted in significant declines in cardiac output. A PEEP of 15 and higher resulted in significant declines in oxygen delivery. As PEEP was increased from 0 to $20, \mathrm{PaO}_{2}$ increased significantly. Gaussian mixture model identified the 0-5 PEEP group as providing optimal cardiac output and oxygen delivery, with PEEP of 5 providing the highest oxygen delivery.

Conclusions: A PEEP of $0-5$ resulted in the optimal oxygen delivery and cardiac output during CPR, with PEEP of 5 resulting in higher oxygen delivery, and a slightly lower, statistically insignificant cardiac output than PEEP of 0.

Keywords: Cardiopulmonary resuscitation, PEEP, Cardiac output, Ventilation, Resuscitation (c) The Author(s). 2020 Open Access This article is licensed under a Creative Commons Attribution 4.0 International License, which permits use, sharing, adaptation, distribution and reproduction in any medium or format, as long as you give appropriate credit to the original author(s) and the source, provide a link to the Creative Commons licence, and indicate if changes were made. The images or other third party material in this article are included in the article's Creative Commons licence, unless indicated otherwise in a credit line to the material. If material is not included in the article's Creative Commons licence and your intended use is not permitted by statutory regulation or exceeds the permitted use, you will need to obtain permission directly from the copyright holder. To view a copy of this licence, visit http://creativecommons.org/licenses/by/4.0/. 


\section{Background}

Even though the importance of providing intermittent positive pressure ventilation during cardiopulmonary resuscitation (CPR) is recognized, the utilization of positive endexpiratory pressure (PEEP) in between breaths is a matter of debate.

Typically, when providing positive pressure ventilation, PEEP is used to prevent alveolar collapse, improve lung compliance, increase functional residual capacity, and maintain the adequate surface area of the lung for oxygen delivery $\left(\mathrm{DO}_{2}\right)$ [1]. However, current CPR guidelines do not discuss whether PEEP should be used during CPR. A recent survey regarding how practitioners ventilate patients during CPR demonstrated a divergence of opinions as to whether or not PEEP is used, and how much PEEP is used during CPR [2]. Some believe, based on older studies, that during CPR, PEEP can potentially lead to a decline in cardiac output (CO) through a complex series of cardiopulmonary interactions [3, 4]. However, PEEP may be necessary to ensure adequate alveolar gas exchange during CPR. It has been shown that lack of PEEP use during CPR has been associated with hypercarbia and relative hypoxia compared with when PEEP is used $[4,5]$. Some providers remain hesitant to supply any PEEP during CPR due to a concern that the potential decrease in CO caused by the use of PEEP will offset the benefit gained by improved gas exchange [2,6]. Considering the contrast in PEEP effects on $\mathrm{CO}$ and $\mathrm{PaO}_{2}$, we hypothesized that there will be a clinically relevant PEEP level that optimizes $\mathrm{CO}$ and $\mathrm{DO}_{2}$ to the tissues during CPR. As such, we sought to evaluate the effect of PEEP on $\mathrm{CO}, \mathrm{PaO}_{2}$, and $\mathrm{DO}_{2}$ during CPR to determine the optimum PEEP for $\mathrm{CO}, \mathrm{PaO}_{2}$, and $\mathrm{DO}_{2}$ to the tissues during CPR.

\section{Methods}

\section{Anesthesia and monitoring}

This study was performed with 25 Landrace-Yorkshire pigs weighing $27-37 \mathrm{~kg}$. The animals were purchased from the supplier on the day of the experiment and were not housed within our facility prior to the experiment. The experimental protocol was approved by the Nemours Animal Care and Usage Committee. The care and handling of the animals were in accord with the National Institutes of Health guidelines. The pigs received initial sedation with two intramuscular injections $10 \mathrm{~min}$ apart of $1 \mathrm{ml} / \mathrm{kg}$ of $\mathrm{KAX}$, an anesthetic cocktail containing ketamine $23 \mathrm{mg} / \mathrm{ml}$, acepromazine $0.58 \mathrm{mg} / \mathrm{ml}$, and xylazine $0.8 \mathrm{mg} / \mathrm{ml}$. Following the initial sedation, a left carotid intra-arterial catheter and right internal jugular central venous catheter were placed using standard cutdown techniques. The pigs were then intubated via midline tracheostomy using a cuffed 7.0-7.5 endotracheal tube. The animals were connected to a ventilator (Servo-I, Getinge, Wayne, NJ USA) and ventilated using volume control mode ventilation, with a tidal volume of $8 \mathrm{ml} / \mathrm{kg}$, a rate of 20 breaths per minute, PEEP of $5 \mathrm{cmH}_{2} \mathrm{O}$, and $\mathrm{FiO}_{2}$ of 1.0. The ventilator breath rate was subsequently adjusted to maintain $\mathrm{pH}$ in the 7.35-7.45 range. The pigs then were given a bolus dose of propofol $1 \mathrm{mg} / \mathrm{kg}$ and ketamine $15 \mathrm{mg} / \mathrm{kg}$ and placed on infusions of propofol $3 \mathrm{mg} / \mathrm{kg} / \mathrm{h}$ and ketamine $15 \mathrm{mg} / \mathrm{kg} /$ $\mathrm{h}$. Bolus doses were repeated, and the continuous infusions were increased if the pig showed signs of pain, such as flinching, or a $10 \%$ increase in heart rate or blood pressure to a hoof pinch with a clamp. Intramuscular anesthesia (choice of medications and dosing) was based on a protocol used in our laboratory for prior studies. Intravenous 
anesthetic medications and dosing were based on published recommendations [7, 8]. The pigs were then given a 30-min stabilization period. Throughout the duration of the study, the pigs received continuous monitoring of heart rate, blood pressure, respiratory rate, and end-tidal carbon dioxide.

\section{Experimental protocol}

The COstatus CO monitor (Transonic Systems, Ithaca, New York USA) was connected to the central venous line as well as the arterial line. The COstatus system measures $\mathrm{CO}$ using ultrasound dilution technology. This device has been validated, in humans as well as in a pig model, for $\mathrm{CO}$ measurements by comparison to thermodilution [9-13]. Baseline (pre-cardiac arrest) $\mathrm{CO}$ measurements and arterial blood gases were obtained (Nova Biomedical, Stat Profile Prime Analyzers, Waltham, MA USA). Bupivacaine 6-9 $\mathrm{mg} / \mathrm{kg}$ was administered intravenously. This dose of bupivacaine has been shown to cause an irreversible cardiac arrest in a porcine model $[14,15]$. Cardiac arrest was confirmed by looking for asystole on the three-lead cardiac monitor, as well as signs of no blood-flow (loss of pulsatile arterial line tracing, loss of pulse oximeter tracing, and loss of end-tidal $\mathrm{CO}_{2}$ tracing) for a full minute. After 1 min of cardiac arrest, a LUCAS 3 mechanical CPR compression device (Stryker, Kalamazoo, MI USA) was applied to the pig, and compressions were started at a rate of 100 compressions per minute.

Using a lottery system for randomization, the pig was then placed on one of five PEEP levels: $0,5,10,15$, and $20 \mathrm{cmH}_{2} \mathrm{O}$. The pig was maintained on each PEEP level for 9 min. Cardiac output was measured twice for each PEEP level, one at $5 \mathrm{~min}$ and a second measurement at $9 \mathrm{~min}$, with the two values averaged together to give a $\mathrm{CO}$ for each PEEP level. Arterial blood gas was obtained at the end of the 9-min period for each PEEP level that the pig was on. The ventilator was then changed to the next randomly selected PEEP level. This process was repeated for all five PEEP levels. Oxygen delivery was calculated using the equation: $\mathrm{DO}_{2}=\left[\left(1.34 \times\right.\right.$ hemoglobin $\left.\times \mathrm{SpO}_{2}\right)+$ $\left.\left(0.0031 \times \mathrm{PaO}_{2}\right)\right] \times(\mathrm{CO} \times 10)$.

\section{Statistical analysis}

Baseline physiologic characteristics including weight and cardiovascular parameters are summarized using mean and standard error of mean. A mixed-effects repeatedmeasures analysis of variance was used to compare the baseline value adjusted mean $\mathrm{CO}, \mathrm{PaO}_{2}$, and $\mathrm{DO}_{2}$ between PEEP groups. Cardiac output, $\mathrm{PaO}_{2}$, and $\mathrm{DO}_{2}$ were used as the response variables; while piglet identification number was used as the random effect; and PEEP group, measurement time-points, and corresponding baseline values were used as fixed effects in each model. The least significant difference test was used to conduct pairwise comparisons between the PEEP groups. Model assumptions were checked before analysis. To decide the optimum PEEP level, we applied the Gaussian mixture model on the adjusted means of $\mathrm{CO}$ and $\mathrm{DO}_{2}$. All tests were two-tailed at an overall level of significance of 0.05. Statistical software SAS version 9.4 (Cary, NC USA) was used for the analysis. A sample size of 25 piglets was used in this study based on an a priori power (80\%) estimation to detect the significant difference (overall) in post$\mathrm{CPR}$ mean $\mathrm{CO}$ and $\mathrm{DO}_{2}$ between PEEP levels. Post-CPR outcome variables were 
measured at five time points for each piglet. The PEEP levels were assigned to time points randomly.

\section{Results}

Twenty-five piglets with mean (standard error or mean) weight of $34.8(0.41) \mathrm{kg}$ were used in the study. Baseline cardiovascular parameters including $\mathrm{CO}, \mathrm{PaO}_{2}$, and $\mathrm{DO}_{2}$ are summarized in Table 1.

The estimated means of $\mathrm{CO}$ for each of the five PEEP levels during CPR, after adjustment for baseline $\mathrm{CO}$ and time of the measurements, are summarized in Table 2 and shown in Fig. 1. The $P$ value $<0.001$ indicates a significant overall mean difference of $\mathrm{CO}$ among PEEP levels, such that as the PEEP increases, $\mathrm{CO}$ decreases monotonically. Pairwise comparisons of $\mathrm{CO}$ for the different PEEP levels are listed in Table 3. As demonstrated, there is no significant drop in $\mathrm{CO}$ as PEEP is increased from 0 to 5 . However, there is a significant drop in CO as PEEP is increased from 0 to $10 \mathrm{cmH}_{2} \mathrm{O}$ $(P=0.006)$ and from 5 to $10 \mathrm{cmH}_{2} \mathrm{O}(P=0.046)$. As noted previously, $\mathrm{CO}$ continues to decrease monotonically as PEEP is further increased. No significant difference in mean $\mathrm{CO}$ was observed between PEEP levels 10 and $15 \mathrm{cmH}_{2} \mathrm{O}$. Finally, it is most noteworthy that mean $\mathrm{CO}$ at PEEP $=20 \mathrm{cmH}_{2} \mathrm{O}$ is substantially smaller than that any other level. Note that at a PEEP of $5 \mathrm{cmH}_{2} \mathrm{O}$ during CPR, CO was approximately $30 \%$ of baseline $\mathrm{CO}$ (also at a PEEP of $5 \mathrm{cmH}_{2} \mathrm{O}$ ).

The estimated mean $\mathrm{DO}_{2}$ for all PEEP levels, after adjustment for baseline values as well as the time the measurements were obtained, are summarized in Table 2 and shown in Fig. 2. The $P$ value of $<0.001$ indicates a significant overall difference in $\mathrm{DO}_{2}$, such that as PEEP increases, $\mathrm{DO}_{2}$ significantly decreases with the exception of 0 to 5 $\mathrm{cmH}_{2} \mathrm{O}$ PEEP, which resulted in a slight nonsignificant increase in $\mathrm{DO}_{2}$. As shown in Fig. 2 and summarized in Table 3, pairwise comparisons of $\mathrm{DO}_{2}$ for the different PEEP levels further demonstrate that compared with PEEP of 0 and $5 \mathrm{cmH}_{2} \mathrm{O}$, a PEEP of 15 and $20 \mathrm{cmH}_{2} \mathrm{O}$ resulted in a significant decline in $\mathrm{DO}_{2}$. A PEEP of 10 did not result in a significant decline in $\mathrm{DO}_{2}$ when compared with either a PEEP of 0 or $5 \mathrm{cmH}_{2} \mathrm{O}$. As shown, mean $\mathrm{DO}_{2}$ was maximum for PEEP of $5 \mathrm{cmH}_{2} \mathrm{O}$.

Table 1 Baseline physiologic characteristics

\begin{tabular}{ll}
\hline Variables & Mean (SEM) \\
\hline Blood chemistry & $7.39(0.01)$ \\
$\mathrm{pH}$ & $40.94(0.79)$ \\
$\mathrm{PCO}_{2}(\mathrm{mmHg})$ & $397.09(13.14)$ \\
$\mathrm{PaO}_{2}(\mathrm{mmHg})$ & $8.39(0.24)$ \\
Hemoglobin $(\mathrm{gm} / \mathrm{dL})$ & $100(0.04)$ \\
Oxygen saturation (\%) & $407.7(31.0)$ \\
Oxygen delivery $(\mathrm{ml} / \mathrm{min})$ & \\
Cardiovascular parameters & $85.12(2.77)$ \\
BP systolic (mmHg) & $58.08(2.29)$ \\
BP diastolic (mmHg) & $95.52(4.32)$ \\
Heart rate (beats/min) & $3.21(0.22)$ \\
Cardiac output $(\mathrm{m} / \mathrm{min})$ & \\
\hline
\end{tabular}

$B P$ blood pressure, SEM standard error of mean 
Table 2 Primary outcomes: mean $\mathrm{CO}, \mathrm{PaO}_{2}$, and oxygen delivery after adjustment for time and baseline values

\begin{tabular}{llll}
\hline PEEP level & Cardiac output $(1 / \mathrm{min})$ & $\mathrm{PaO}_{\mathbf{2}}(\mathrm{mmHg})$ & Oxygen delivery $(\mathrm{ml} / \mathrm{min})$ \\
\hline 0 & $1.04(0.06)$ & $154.54(24.75)$ & $107.72(6.77)$ \\
5 & $1(0.06)$ & $201.83(24.79)$ & $110.78(6.79)$ \\
10 & $0.87(0.06)$ & $205.53(24.72)$ & $100.9(6.77)$ \\
15 & $0.86(0.06)$ & $221.81(24.74)$ & $94.6(6.77)$ \\
20 & $0.73(0.06)$ & $266.73(24.76)$ & $81.95(6.79)$ \\
$P$ value & $<.001$ & $<.001$ & $<.001$ \\
\hline
\end{tabular}

Note: $P$ value indicates the significance to compare the overall mean differences across PEEP levels. CO cardiac output, PEEP positive end-expiratory pressure

The estimated mean $\mathrm{PaO}_{2}$ after adjustment for baseline $\mathrm{PaO}_{2}$ and time is summarized in Table 2 and illustrated in Fig. 3. After adjustment for the time of measurements and the baseline $\mathrm{PaO}_{2}$, there is a significant difference in mean $\mathrm{PaO}_{2}$ between PEEP levels demonstrating that as PEEP increases, $\mathrm{PaO}_{2}$ monotonically increases $(P$ value $<0.001)$. However, as demonstrated in Table 3, when a pairwise comparison of $\mathrm{PaO}_{2}$ for the different PEEP levels is performed, increases in PEEP above 0 result in significant increases in $\mathrm{PaO}_{2}$ : PEEP $0-5 \mathrm{cmH}_{2} \mathrm{O}(P=0.002)$, PEEP $0-10 \mathrm{cmH}_{2} \mathrm{O}(P<$ 0.006), PEEP $0-15 \mathrm{cmH}_{2} \mathrm{O}(P<0.003)$, and PEEP $0-20 \mathrm{cmH}_{2} \mathrm{O}(P<0.001)$. Compared with PEEP of $5 \mathrm{cmH}_{2} \mathrm{O}$, PEEP of 15 and $20 \mathrm{cmH}_{2} \mathrm{O}$ have a significant increase in $\mathrm{PaO}_{2}$.

Application of the Gaussian mixture model on adjusted means of $\mathrm{CO}$ and $\mathrm{DO}_{2}$ (to determine the optimal PEEP level) demonstrate three distinct groups of PEEP levels with 0 and

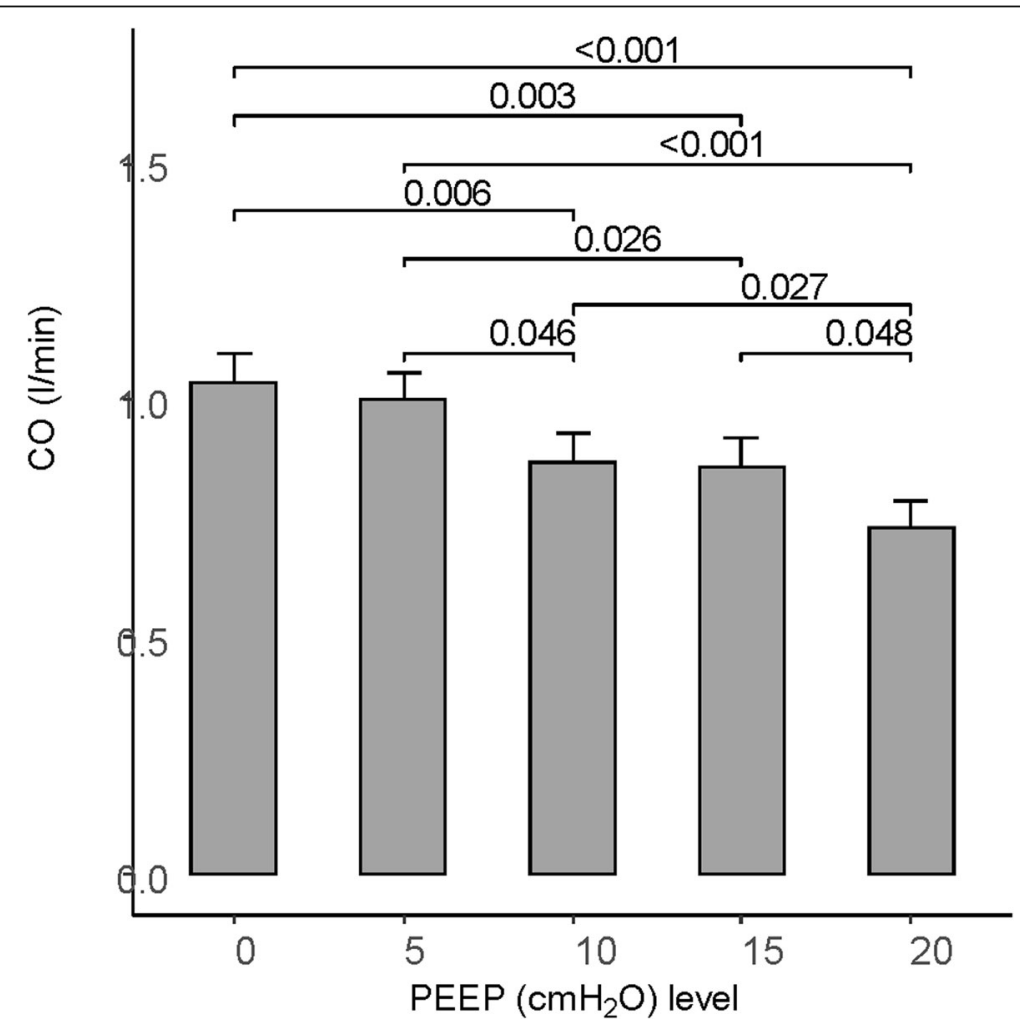

Fig. 1 Comparison of cardiac output for the different positive end-expiratory pressure (PEEP) levels during cardiopulmonary resuscitation. CO cardiac output 
Table 3 Pairwise comparisons of main outcomes across positive end-expiratory pressure levels

\begin{tabular}{|c|c|c|c|c|c|c|c|}
\hline \multirow{2}{*}{\multicolumn{2}{|c|}{$\begin{array}{l}\text { PEEP level } \\
\text { pairs }\end{array}$}} & \multicolumn{2}{|c|}{ Cardiac output (I/min) } & \multicolumn{2}{|l|}{$\mathrm{PaO}_{\mathbf{2}}(\mathrm{mmHg})$} & \multicolumn{2}{|c|}{ Oxygen delivery (ml/min) } \\
\hline & & \multirow{2}{*}{$\begin{array}{l}\text { MeanDiff (SEM) } \\
0.05(0.06)\end{array}$} & \multirow{2}{*}{$\frac{P}{.45}$} & \multirow{2}{*}{$\begin{array}{l}\text { MeanDiff (SEM) } \\
-47.29(14.48)\end{array}$} & \multirow{2}{*}{$\begin{array}{l}\boldsymbol{P} \\
.002\end{array}$} & \multirow{2}{*}{$\begin{array}{l}\text { MeanDiff (SEM) } \\
-3.05(6.69)\end{array}$} & \multirow{2}{*}{$\begin{array}{l}P \\
.649\end{array}$} \\
\hline 0 & 5 & & & & & & \\
\hline 0 & 10 & $0.17(0.06)$ & .006 & $-51(13.99)$ & $<.001$ & $6.82(6.46)$ & .294 \\
\hline 0 & 15 & $0.18(0.06)$ & .003 & $-67.27(13.91)$ & $<.001$ & $13.12(6.43)$ & .044 \\
\hline 0 & 20 & $0.31(0.06)$ & $<.001$ & $-112.19(13.98)$ & $<.001$ & $25.77(6.46)$ & $<.001$ \\
\hline 5 & 10 & $0.12(0.06)$ & .046 & $-3.7(14.14)$ & .794 & $9.88(6.54)$ & .135 \\
\hline 5 & 15 & $0.14(0.06)$ & .026 & $-19.98(13.92)$ & .155 & $16.18(6.44)$ & .014 \\
\hline 5 & 20 & $0.26(0.06)$ & $<.001$ & $-64.9(13.61)$ & $<.001$ & $28.82(6.31)$ & $<.001$ \\
\hline 10 & 15 & $0.01(0.06)$ & .843 & $-16.28(14.21)$ & .255 & $6.3(6.54)$ & .338 \\
\hline 10 & 20 & $0.14(0.06)$ & .027 & $-61.2(14.58)$ & $<.001$ & $18.95(6.71)$ & .006 \\
\hline 15 & 20 & $0.13(0.06)$ & .048 & $-44.92(14.97)$ & .003 & $12.65(6.86)$ & .068 \\
\hline
\end{tabular}

MeanDiff mean difference, PEEP positive end-expiratory pressure, SEM standard error of mean

$5 \mathrm{cmH}_{2} \mathrm{O}$ in one group, 10 and $15 \mathrm{cmH}_{2} \mathrm{O}$ in another group, and PEEP level $20 \mathrm{cmH}_{2} \mathrm{O}$ as a distinct group, with PEEP $0-5 \mathrm{cmH}_{2} \mathrm{O}$ as the optimal PEEP level for $\mathrm{CO}$ and $\mathrm{DO}_{2}$.

\section{Discussion}

When lung compliance is poor such as in patients with pneumonia or bronchiolitis or when there is excess lung fluid for example with pulmonary edema, the critical closing

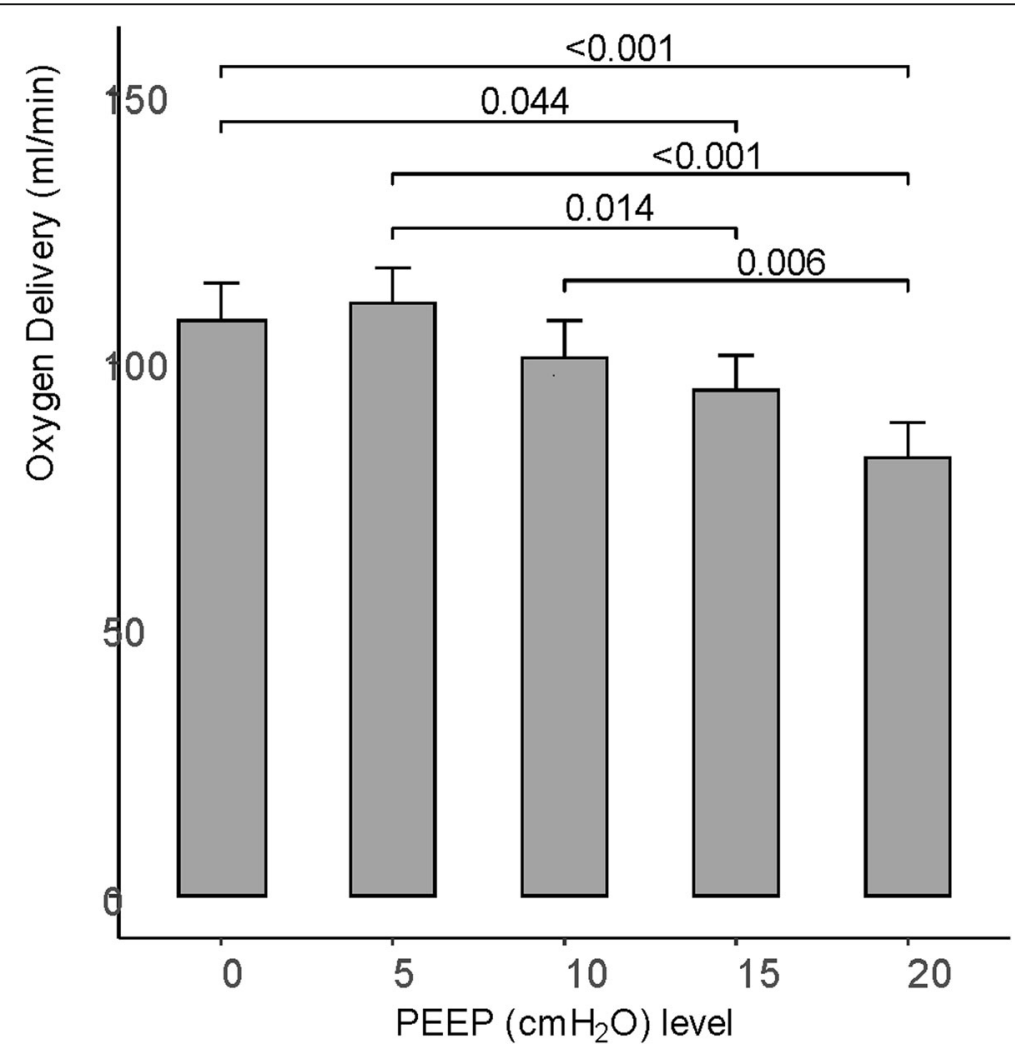

Fig. 2 Comparison of oxygen delivery for the different positive end-expiratory pressure (PEEP) levels during cardiopulmonary resuscitation 


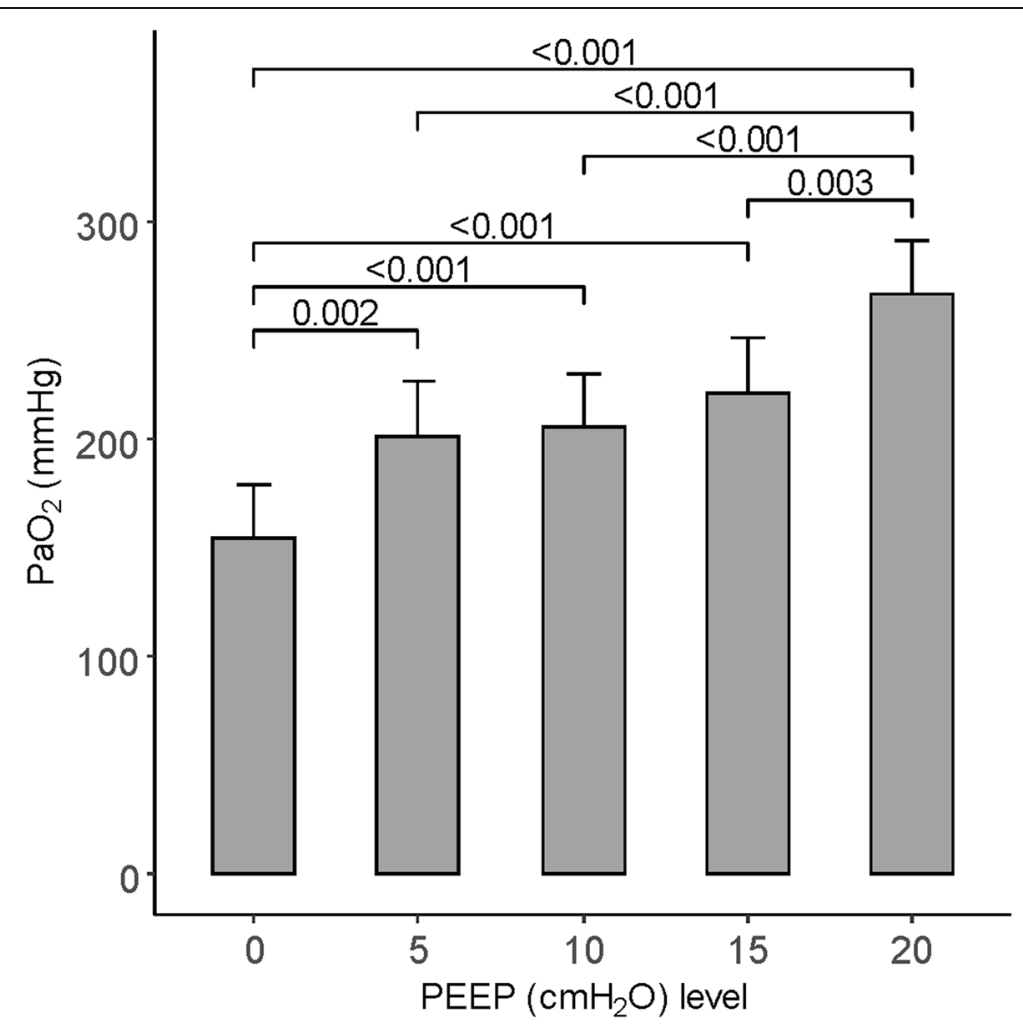

Fig. 3 Comparison of $\mathrm{PaO}_{2}$ for the different positive end-expiratory pressure (PEEP) levels during cardiopulmonary resuscitation

pressure is increased, and lungs become more likely to collapse. During mechanical ventilation, by maintaining the PEEP above the critical closing pressure, alveolar collapse can be prevented [1].

Through a complex series of cardiopulmonary interactions, PEEP can potentially have a direct impact on $\mathrm{CO}$. The blood in the venous system relies on the pressure difference generated by the venous blood, the mean systemic pressure, and the right atrium to promote the forward flow of blood back to the heart. This difference between the mean systemic pressure and the right atrial pressure is the driving force for the preload [16-18]. When PEEP is used, the increase in alveolar pressure is transmitted to the entire thorax, potentially increasing the right atrial pressure and thereby reducing the pressure difference between the mean systemic pressure and the right atrial pressure. If the decrease in this pressure gradient is significant enough, it can result in decreased venous return to the heart, decreasing cardiac output $[19,20]$. The exact impact that this effect has is questionable, as a study by Jellinek et al. demonstrated that positive pressure increases both the right atrial pressure as well as the mean systemic pressure proportionally, resulting in no change in the mean systolic pressure-right atrium pressure gradient [21]. The use of too much PEEP can over-distend alveoli resulting in mechanical compression of the pulmonary capillaries, increasing the right ventricular (RV) afterload. An increase in the RV afterload can over-distend the RV, causing bowing of the ventricular septum into the left ventricular (LV), thereby further decreasing the volume of the LV, decreasing LV filling, and reducing CO. On the left side of the heart, PEEP can shift the LV pressure-volume curve to the left, indicating a decrease in 
LV distensibility. Thus, given that during CPR blood flow and venous return are already compromised as optimal CPR generates only $15 \%$ to $25 \%$ of normal CO [22], these effects of PEEP on CO can potentially diminish an already severely compromised CO.

Conversely, although an inappropriate amount of PEEP can have a detrimental effect on $\mathrm{CO}$, using an appropriate amount of PEEP can potentially augment $\mathrm{CO}$. Increasing the intrathoracic pressure can decrease the LV afterload, thereby improving the $\mathrm{CO}$, especially in the setting of a poorly functioning LV. Additionally, the correct amount of PEEP can optimize peripheral vascular resistance, thereby improving LV preload $[1,19,20]$.

The use of PEEP can potentially play a significant role in the ability to ventilate patients receiving CPR. Studies performed by the Cardiac Arrest and Ventilation International Association for Research Group demonstrated that in a cadaver model and a bench model of CPR, as well as in a clinical study analyzing capnograms of intubated patients receiving $\mathrm{CPR}$, intrathoracic airway closure occurs in patients receiving CPR, which can limit ventilation. This airway closure was mitigated by the use of PEEP up to $10 \mathrm{cmH}_{2} \mathrm{O}$, which also caused some degree of ventilation to occur with the oscillations of air generated by the change in intrathoracic pressure that occurs during the compression and decompression phase of chest compressions [23, 24]. The effect that using no PEEP potentially has on oxygenation and $\mathrm{DO}_{2}$ to the tissues during $\mathrm{CPR}$ is also unknown.

There are currently no studies directly evaluating the effect of PEEP on CO during $\mathrm{CPR}$. There is also currently no consensus whether or not PEEP should be applied during CPR, and if used, how much PEEP should be applied. The aim of this study was to evaluate the effect of PEEP on $\mathrm{CO}$ and $\mathrm{DO}_{2}$ during CPR and to determine the ideal PEEP to maximize $\mathrm{DO}_{2}$ by augmenting both $\mathrm{CO}$ and arterial oxygen concentration during CPR.

The results of this study demonstrate that as PEEP is increased from 0 to $20 \mathrm{cmH}_{2} \mathrm{O}$, there is a significant decline in $\mathrm{CO}$ and $\mathrm{DO}_{2}$. Increasing the PEEP from 0 to $5 \mathrm{cmH}_{2} \mathrm{O}$ results in a slight, statistically insignificant, decrease in $\mathrm{CO}$, and increase in $\mathrm{DO}_{2}$. Further increases in PEEP to $10 \mathrm{cmH}_{2} \mathrm{O}$ and above result in significant drops in $\mathrm{CO}$. Even compared with PEEP of $5 \mathrm{cmH}_{2} \mathrm{O}$, PEEP of $10 \mathrm{cmH}_{2} \mathrm{O}$ showed a significant decline in CO. For $\mathrm{DO}_{2}$, compared with both PEEP of 0 and $5 \mathrm{cmH}_{2} \mathrm{O}$, once PEEP $15 \mathrm{cmH}_{2} \mathrm{O}$ and higher is reached, there is a statistically significant drop in $\mathrm{DO}_{2}$. In evaluating the effect of PEEP on $\mathrm{PaO}_{2}$ during CPR, as PEEP is increased from 0 to $20 \mathrm{cmH}_{2} \mathrm{O}$, there is a significant increase seen in $\mathrm{PaO}_{2}$. Compared with a PEEP of $0 \mathrm{cmH}_{2} \mathrm{O}$, PEEP of 5, 10, and $15 \mathrm{cmH}_{2} \mathrm{O}$ all had significantly higher $\mathrm{PaO}_{2}$. Compared with PEEP of $5 \mathrm{cmH}_{2} \mathrm{O}$, only PEEP of $20 \mathrm{cmH}_{2} \mathrm{O}$ had a significantly higher $\mathrm{PaO}_{2}$.

Using the Gaussian mixture model on adjusted means of $\mathrm{CO}$ and $\mathrm{DO}_{2}$, there were three groups of homogeneous PEEP that were identified: $0-5,10-15$, and $20 \mathrm{cmH}_{2} \mathrm{O}$. $\mathrm{PaO}_{2}$ was not included in this analysis because even the lowest PEEP had a $\mathrm{PaO}_{2}$ of 154 , which is physiologic, representing an oxygen saturation of $100 \%$ and is likely adequate for CPR. In addition, the importance of $\mathrm{PaO}_{2}$ is likely to be in the amount of oxygen delivered to the tissues during $\mathrm{CPR}$, making $\mathrm{DO}_{2}$ the more important variable. Based on these results, assuming that the lungs are not acutely ill or poorly compliant, our results demonstrate that the $0-5 \mathrm{cmH}_{2} \mathrm{O}$ PEEP group provides optimal $\mathrm{CO}$ and $\mathrm{DO}_{2}$, with PEEP of $5 \mathrm{cmH}_{2} \mathrm{O}$ providing the highest $\mathrm{DO}_{2}$ overall, with an insignificant difference in $\mathrm{CO}$ between PEEP of $0 \mathrm{cmH}_{2} \mathrm{O}$ and $5 \mathrm{cmH}_{2} \mathrm{O}$. Thus, based on these results, it appears that PEEP of $5 \mathrm{cmH}_{2} \mathrm{O}$ would be the optimal PEEP for ventilating patients during CPR. 
This study has a number of limitations. Most CPR studies are done on animals or other non-human models, and the porcine model is commonly used as a model for cardiac arrest because the physiology approximates that of humans [14]. However, it has to be acknowledged that there are differences in cardiovascular physiology between humans and pigs, such as different thorax geometry [24], which makes it an imperfect model for CPR physiology in humans. Also, the outcomes in this study are meant to evaluate cardiovascular parameters during CPR, with the goal of optimizing organ perfusion during CPR. However, there is no evidence that following the conclusions in this study will directly lead to a better outcome in cardiac arrest patients. However, we do feel that to give providers the best chance at successfully resuscitating a patient, CPR must be optimized, and adjusting the PEEP to achieve optimal oxygen delivery is a potential area of optimization. Ideally, these findings should be verified with a proper trial in humans; however, such a trial may be extremely difficult to design and implement. Although CPR is not typically performed with patients on a ventilator, PEEP adjustments can be made through the PEEP valve on a bag-valve-mask device. Finally, the goal of this study was to isolate the effect of PEEP on CO. To accomplish this, slight adjustments were made to optimize physiologic parameters, such as allowing the animal to tolerate $60 \mathrm{~min}$ of CPR, which is not typically done when performing CPR on humans. For example, the respiratory rate was higher than the 10 breaths per minute currently recommended during continuous compression CPR to achieve and maintain a physiologic $\mathrm{pH}$ prior to and during CPR. Along the same lines, the decision was made to maintain the animal on each PEEP level for $9 \mathrm{~min}$, with $1 \mathrm{~min}$ in between to draw the arterial blood gas and reconnect cardiac output monitor to maintain the entire duration of CPR less than $1 \mathrm{~h}$. We felt that if the compressions were to continue for more than an hour, the animals would be less stable for the final PEEP levels, which would introduce another variable into the equation. By keeping the total compression time less than $1 \mathrm{~h}$, we felt that the animal would be able to tolerate the entire course of compressions, whereas extending the overall time of compressions would have risked greater instability towards the end, compared with the beginning. Using a two-way analysis of variance paradigm for the statistical analysis took into account PEEP level as well as time duration in the final analysis. If the animals were unstable for the final PEEP levels, this would have added an additional variable that would have been difficult to account for. In addition, after initiating cardiac arrest and during the $60 \mathrm{~s}$ prior to initiation of chest compression, the pigs were ventilated using a PEEP of $5 \mathrm{cmH}_{2} \mathrm{O}$ to avoid alveolar collapse prior to the implementation of the study protocol, despite this differing from what occurs in typical cardiac arrest patients, who are not receiving PEEP when they go into cardiac arrest. We feel that these do not detract from the results of this study, as the goal of the study is to look at the effect PEEP has on CO, which this study certainly does.

\section{Conclusions}

In this study, analyzing the effect of PEEP on $\mathrm{CO}, \mathrm{PaO}_{2}$, and $\mathrm{DO}_{2}$ during CPR, PEEP of $0-5 \mathrm{cmH}_{2} \mathrm{O}$ resulted in the optimal $\mathrm{DO}_{2}$ and $\mathrm{CO}$, with PEEP of 5 resulting in a higher $\mathrm{DO}_{2}$, and a slightly lower, statistically insignificant, $\mathrm{CO}$ than PEEP of 0 . Thus, based on the contrasting effects of PEEP on $\mathrm{CO}, \mathrm{PaO}_{2}$, and $\mathrm{DO}_{2}$, the results of our study would suggest a PEEP of $5 \mathrm{cmH}_{2} \mathrm{O}$ is the optimum PEEP level for performing CPR, at least in this model of CPR for cardiac arrest. 


\section{Abbreviations}

CO: Cardiac output; CPR: Cardiopulmonary resuscitation; $\mathrm{DO}_{2}$ : Oxygen delivery; LV: Left ventricular; PEEP: Positive endexpiratory pressure; RV: Right ventricular

\section{Acknowledgements}

We acknowledge Fredrik Arnwald for his assistance in designing the study protocol.

\section{Authors' contributions}

YL made substantial contributions to the conception, design of the work acquisition and analysis, interpretation of data, and drafting of and substantial revision of the work. MJH made substantial contributions to the interpretation of data. JPK made substantial contributions to the design of the work, acquisition and analysis, and interpretation of data. $\mathrm{KB}$ made substantial contributions to the design of the work, acquisition and analysis, and interpretation of data. AH made substantial contributions to the design of the work and acquisition and analysis. TS made substantial contributions to the design of the work, acquisition and analysis, interpretation of data, and drafting of and substantial revision of the work. All authors approved the submitted version (and any substantially modified version that involves the author's contribution to the study); and agrees both to be personally accountable for the author's own contributions and to ensure that questions related to the accuracy or integrity of any part of the work, even ones in which the author was not personally involved, are appropriately investigated, resolved, and the resolution documented in the literature.

\section{Funding}

Yosef Levenbrown is currently receiving an NIH COBRE Grant, P30GM114736.

\section{Availability of data and materials}

Datasets used and/or analyzed during the current study are available from the corresponding author on reasonable request.

\section{Ethics approval}

The animals were purchased from the supplier on the day of the experiment and were not housed within our facility prior to the experiment. The experimental protocol was approved by the Nemours Animal Care and Usage Committee. The care and handling of the animals were in accord with the National Institutes of Health guidelines.

\section{Consent for publication}

Not applicable.

\section{Competing interests}

The authors declare that they have no competing interests.

\section{Author details}

'Division of Pediatric Critical Care, Nemours/Alfred I. duPont Hospital for Children, 1600 Rockland Road, Wilmington DE 19803, USA. ²Department of Pediatrics, Sidney Kimmel Medical School, Thomas Jefferson University, Philadelphia, PA, USA. ${ }^{3}$ Nemours Biomedical Research, Wilmington, DE, USA. ${ }^{4}$ Department of Applied Economics and Statistics, University of Delaware, Newark, DE, USA. ${ }^{5}$ Department of Respiratory Care, Nemours/Alfred I. duPont Hospital for Children, Wilmington, DE, USA. ${ }^{6}$ Nemours Biomedical Research/Research Lung Center, Wilmington, DE, USA.

${ }^{7}$ Department of Pediatrics, Lewis Katz School of Medicine at Temple University, Philadelphia, PA, USA.

Received: 6 May 2020 Accepted: 16 July 2020

Published online: 25 July 2020

\section{References}

1. Acosta P, Santisbon E, Varon J (2007) The use of positive end-expiratory pressure in mechanical ventilation. Crit Care Clin 23:251-261

2. Cordioli RL, Brochard L, Suppan L, Lyazidi A, Templier F, Khoury A et al (2018) How ventilation is delivered during cardiopulmonary resuscitation: an international survey. Respir Care 63:1293-1301

3. Colgan FJ, Nichols FA, DeWeese JA (1974) Positive end-expiratory pressure, oxygen transport, and the low-output state. Anesth Analg 53:538-543

4. Hodgkin BC, Lambrew CT, Lawrence FH 3rd, Angelakos ET (1980) Effects of PEEP and of increased frequency of ventilation during CPR. Crit Care Med 8:123-126

5. Hevesi ZG, Thrush DN, Downs JB, Smith RA (1999) Cardiopulmonary resuscitation: effect of CPAP on gas exchange during chest compressions. Anesthesiology 90:1078-1083

6. Cordioli RL, Grieco DL, Charbonney E, Richard JC, Savary D (2019) New physiological insights in ventilation during cardiopulmonary resuscitation. Curr Opin Crit Care 25:37-44

7. Levenbrown Y, Penfil S, Rodriguez E, Zhu Y, Bhat AM, Hesek A et al (2013) Use of insulin to decrease septic shockinduced myocardial depression in a porcine model. Inflammation. 36:1494-1502

8. Swindle MM. Anesthesia \& analgesia in swine. Sinclair bio-resources. https://www.sinclairresearch.com/assets/sites/2/ Anesthesia-Analgesia-Small.pdf. Accessed 27 Feb 2020.

9. Boehne M, Schmidt F, Witt L, Koditz H, Sasse M, Sumpelmann R et al (2012) Comparison of transpulmonary thermodilution and ultrasound dilution technique: novel insights into volumetric parameters from an animal model. Pediatr Cardiol 33:625-632

10. Darling E, Thuramalla N, Searles B (2011) Validation of cardiac output measurement by ultrasound dilution technique with pulmonary artery thermodilution in a pediatric animal model. Pediatr Cardiol 32:585-589 
11. de Boode WP, van Heijst AF, Hopman JC, Tanke RB, van der Hoeven HG, Liem KD (2010) Cardiac output measurement using an ultrasound dilution method: a validation study in ventilated piglets. Pediatr Crit Care Med 11:103-108

12. de Boode WP, van Heijst AF, Hopman JC, Tanke RB, van der Hoeven HG, Liem KD (2010) Application of ultrasound dilution technology for cardiac output measurement: cerebral and systemic hemodynamic consequences in a juvenile animal model. Pediatr Crit Care Med 11:616-623

13. Ruperez M, Lopez-Herce J, Garcia C, Sanchez C, Garcia E, Vigil D (2004) Comparison between cardiac output measured by the pulmonary arterial thermodilution technique and that measured by the femoral arterial thermodilution technique in a pediatric animal model. Pediatr Cardiol 25:119-123

14. Cherry BH, Nguyen AQ, Hollrah RA, Olivencia-Yurvati AH, Mallet RT (2015) Modeling cardiac arrest and resuscitation in the domestic pig. World J Crit Care Med 4:1-12

15. Mayr VD, Raedler C, Wenzel V, Lindner KH, Strohmenger HU (2004) A comparison of epinephrine and vasopressin in a porcine model of cardiac arrest after rapid intravenous injection of bupivacaine. Anesth Analg 98:1426-1431

16. Beard DA, Feigl EO (2011) Understanding Guyton's venous return curves. Am J Physiol Heart Circ Physiol 301:H629H633

17. Guyton AC (1955) Determination of cardiac output by equating venous return curves with cardiac response curves. Physiol Rev 35:123-129

18. Magder S (2012) Bench-to-bedside review: an approach to hemodynamic monitoring--Guyton at the bedside. Crit Care $16: 236$

19. Bronicki RA, Penny DJ, Anas NG, Fuhrman B (2016) Cardiopulmonary interactions. Pediatr Crit Care Med 17:S182-S193

20. Vargas M, Sutherasan Y, Gregoretti C, Pelosi P (2014) PEEP role in ICU and operating room: from pathophysiology to clinical practice. ScientificWorldJournal 2014:852356

21. Jellinek H, Krenn H, Oczenski W, Veit F, Schwarz S (1985) Fitzgerald RD (2000) Influence of positive airway pressure on the pressure gradient for venous return in humans. J Appl Physiol 88:926-932

22. Lurie KG, Nemergut EC, Yannopoulos D, Sweeney M (2016) The physiology of cardiopulmonary resuscitation. Anesth Analg 122:767-783

23. Charbonney E, Delisle S, Savary D, Bronchti G, Rigollot M, Drouet A et al (2018) A new physiological model for studying the effect of chest compression and ventilation during cardiopulmonary resuscitation: the Thiel cadaver. Resuscitation 125:135-142

24. Grieco DL, Brochard LJ, Drouet A, Telias I, Delisle S, Bronchti $\mathrm{G}$ et al (2019) Intrathoracic airway closure impacts $\mathrm{CO}_{2}$ signal and delivered ventilation during cardiopulmonary resuscitation. Am J Respir Crit Care Med 199:728-737

\section{Publisher's Note}

Springer Nature remains neutral with regard to jurisdictional claims in published maps and institutional affiliations.

\section{Submit your manuscript to a SpringerOpen ${ }^{\circ}$ journal and benefit from:}

- Convenient online submission

- Rigorous peer review

- Open access: articles freely available online

High visibility within the field

- Retaining the copyright to your article

Submit your next manuscript at $\boldsymbol{\nabla}$ springeropen.com 